\title{
SPECTROSCOPIC DETERMINATION OF TOTAL PHENOL AND FLAVONOID CONTENTS OF CITRUS LIMON PEEL FROM NORTH EASTERN REGION OF INDIA
}

\author{
Khatiwora Elija $^{1 *}$, Adsul Vaishali B ${ }^{1}$, Torane Rasika $C^{2}$, Gaikwad Sucheta ${ }^{2}$, Deshpande \\ Nirmala $\mathbf{R}^{2}$, Kashalkar Rajashree $\mathbf{V}^{2}$ \\ ${ }^{1}$ Dept. of Chemistry, Y. M. College, Bharati Vidyapeeth University, Pune 411038, India \\ ${ }^{2}$ Dr. T. R. Ingle Research Laboratory, Dept. of Chemistry, Sir Parashurambhau College, Pune 411030, India
}

\section{ABSTRACT}

Citrus fruit plants are valuable sources of phenolic and other biologically active compounds. Phenolic compounds have been reported to have multiple biological effects. In this paper quantitative determination of phenols and flavonoids of citrus limon peel extracts was carried out using spectrophotometric method. The plant material was collected from Assam, north eastern region of India. Total phenolic content was determined by Folin-Ciocalteau method and aluminium chloride method was used for flavonoid determination. Methanol and ethanol extracts of ripe and unripe peel of the plant contain high amount of phenol contents compared to acetone and ethyl acetate extracts. Methanol extract contains maximum and the ethyl acetate shows minimum amount of flavonoid contents. However, all the extracts show significant results.

Key Words: Citrus limon, Phenol, Flavonoid, Catechol and Quercetin.

\section{Article Info}

Received 17 Dec 2016; Review Completed 19 Dec 2016; Accepted 03 Jan 2017, Available online 15 Jan 2017

Cite this article as:

Khatiwora E, Adsul VB, Torane RC, Gaikwad S, Deshpande NR, Kashalkar RV, Spectroscopic determination of total phenol and flavonoid contents of citrus limon peel from north eastern region of India, Journal of Drug Delivery and Therapeutics. 2017 ; $7(1): 21-24$. DOI: http://dx.doi.org/10.22270/jddt.v7i1.1368

*Corresponding author:

Khatiwora Elija, Email: ekhatiwora@yahoo.com, Cell number: +919970502963

\section{INTRODUCTION}

Phenols, sometimes called phenolics are one of the main secondary metabolites present in the plant kingdome.They are commonly found in both edible and non-edible plants. They are reported to have multiple biological effects including antioxidant activity $^{1}$. Flavonoids, the most common group of polyphenolic compounds found ubiquitously in plants. These plant secondary metabolites show anti-allergic, anti-inflammatory and anti-cancer activity. Researchers have become interested in flavonoids and other phenolics for their medicinal properties, especially their potential role in the prevention of cancer and heart diseases ${ }^{1}$. Citrus is the general term for plants belonging to the family Rutaceae ${ }^{2}$. Citrus fruits and derived products have beneficial impacts on the human health ${ }^{3}$. Hence, citrus fruits have attracted much attention because of its nutritional and antioxidant properties. They are important source of many bioactive compounds and widely known for its medicinal impact due to presence of flavenoids, flavenones and other compounds which are rare in other plants.

Citrus limon belongs to family rutaceae is also known as Assam lemon and one of the most important crops of Assam and other parts of north eastern region. Fruit 
is widely used for culinary, beverages, industrial and medicinal uses. The fruits are sour, rich in vitamin $\mathrm{C}$ which helps the body to fight off infections and also to prevent or treat scurvy ${ }^{4}$. Fruits are thermogenic, digestive, carminative, stomachic laxative, stimulant, antiseptic and have mosquito repellent power ${ }^{5}$. Anthelmintic activity Citrus limon fruit empty juice sacs was investigated from Nagpur region of Maharashtra ${ }^{6}$. Comparative study of antioxidants changes including total flavonoid, total phenol and total antioxidant capacity of Citrus limon fruits grown at the north of Iran were examined ${ }^{3}$. Determination of phenolic contents and total antioxidant activity of citrus lemon juice and peel extracts was reported from Bosnia and Herzegovina ${ }^{7}$.Yield, fruit quality, economic feasibility and water productivity of citrus limon plants were evaluated ${ }^{8}$. Work about genetic resources of Citrus of north-eastern India and their potential use was available. Recovery of pectin from C.limon was also reported ${ }^{9}$. Antimicrobial activity of juice in ripens and unripe forms of C.limon were studied from Assam ${ }^{10}$. Pharmacognostic, phytochemical, physicochemical property and antimicrobial activity of lemon peel oil were reported ${ }^{11}$. Phenol and flavonoid contents of Ethanol: water extract of C.limon were reported from Tamilnadu, India ${ }^{12}$.

Preliminary qualitative phytochemical screening of C.limon peel revealed the presence of phenolic compounds, terpenoids, flavonoids and steroids. Some of them have antioxidant and antimicrobial activities. This study presents the quantitative estimation of total phenolic and flavonoid contents of from the ripen and unripe peel of citrus limon fruits available from Biswanath Chariali district, Assam. As per the available reports this is the first study of determining the phenol and flavonoid contents of ethyl acetate, acetone, ethanol and methanol extracts of citrus limon peel collected from Biswanath district, Assam, India.

\section{MATERIAL AND METHOD}

The plant material was collected from Naduar area, Biswanath chariali district, Assam, India.

The plant was authenticated at Department of Life Sciences, Dibrugarh University, Assam, India. FolinCiocalteau reagent and all other chemicals used were Merck products. UV Vis S1700 Pharma spectrophotometer, Schimadzu was used for absorbance measurements.

Preparation of plant extract: Air shade dried and powdered peel material of Citrus limon $(50 \mathrm{mg})$ was treated separately with ethyl acetate, acetone, ethanol and methanol $(250 \mathrm{ml})$ by refluxing for 18 hours. Solvents were recovered under reduced pressure to obtain the crude extracts. Known amounts of dried extracts were dissolved in known volume of methanol and various concentrations of the extract solutions were prepared.

Determination of total phenolics: The total phenolic contents of Citrus limon peel extracts were determined according to the method described by
Malik and Singh ${ }^{13}$. Aliquots of the extracts were taken in a $10 \mathrm{ml}$ glass tube and made up to a volume of $3 \mathrm{ml}$ with distilled water. Folin- Ciocalteau reagent: water $(1: 1,0.5 \mathrm{ml})$ and $\mathrm{Na}_{2} \mathrm{CO}_{3}(20 \%, 2 \mathrm{ml})$ were added sequentially in each tube. A blue color was developed in each tube because the phenols undergo a complex redox reaction with phosphomolybdic acid in folin ciocalteau reagent in alkaline medium which resulted in a blue colored complex, molybdenum blue. The test solutions were warmed for 1 minute, cooled and absorbance was measured at $650 \mathrm{~nm}$ against the reagent used as a blank. A standard calibration plot was generated (Figure-1) at $650 \mathrm{~nm}$ using known concentrations of catechol. The concentrations of phenols in the test samples were calculated from the calibration plot and expressed as $\mathrm{mg}$ catechol equivalent of $\mathrm{phenol} / \mathrm{g}$ of sample.

Determination of total flavonoids: The aluminum chloride method was used for the determination of the total flavonoid content of the sample extracts ${ }^{14}$. Aliquots of extract solutions were taken and made up the volume to $3 \mathrm{ml}$ with methanol. Then $\mathrm{AlCl}_{3}(10 \%$, $0.1 \mathrm{ml})$, Na-K tartarate $(0.1 \mathrm{ml})$ and $2.8 \mathrm{ml}$ distilled water were added sequentially. The test solution was vigorously shaken. Absorbance at $415 \mathrm{~nm}$ was recorded after 30 minutes of incubation. A standard calibration plot was generated (Figure-2) at $415 \mathrm{~nm}$ using known concentrations of quercetin. The concentrations of flavonoid in the test samples were calculated from the calibration plot and expressed as mg quercetin equivalent /g of sample.

\section{RESULT AND DISCUSSION}

Ethyl acetate, acetone, ethanol and methanol extracts of ripen and unripe peel of Citrus limon were subjected to screening for their total phenolic contents and total flavonoid contents.Table-1 presents the total phenolic contents of Citrus limon peel extracts. Table 2 presents total flavonoids content of various extracts of Citrus limon peel.

The present study revealed the phenolic contents of ethyl acetate, acetone, ethanol and methanol extract of Citrus limon peel in terms of $\mathrm{mg}$ catechol equivalent/g of sample (standard plot: $\mathrm{y}=0.0966 \mathrm{x}, \mathrm{R}^{2}=0.9878$ ). The values were found between $190 \mathrm{mg}$ to $395 \mathrm{mg}$ catechol equivalent /g for ripen peel extracts. The values for unripe peel extracts were $155 \mathrm{mg}$ to $367 \mathrm{mg}$ catechol equivalent /g sample. The phenolics content of ethanol and methanol extracts were quite high compared to acetone and ethyl acetate extracts for both ripen and unripe peel. Phenolics present in the plant have received considerable attention because of their potential biological activities. The antioxidant activity of phenolics is mainly due to their redox properties, which allow them to act as reducing agents, hydrogen donors and singlet oxygen quenchers.

Flavonoids as one of the most diverse and widespread group of natural compounds are probably the most important natural phenols. These compounds possess a broad spectrum of chemical and biological activities including radical scavenging properties. Using the 
standard plot of quercetin $\left(y=0.0148 x, R^{2}=0.975\right)$, the flavonoid contents of ethyl acetate, acetone, ethanol and methanol extracts of Citrus limon peel were found ranging from 270 to $460 \mathrm{mg}$ quercetin equivalent/g of sample for ripen peel extracts. These values for unripe peel extracts were $245 \mathrm{mg}$ to $425 \mathrm{mg}$ quercetin equivalent/g of sample. Methanol extract contains the maximum and ethyl acetate extract contains the minimum amount of flavonoid content for both the ripen and unripe peel extracts. Ethanol and methanol extracts show good amount of flavonoid contents in both the cases.

Table 1: Phenol contents

\begin{tabular}{|l|c|c|}
\hline \multirow{2}{*}{ Extracts } & \multicolumn{2}{|c|}{ Phenol content(mg catechol equivalent / g material) } \\
\cline { 2 - 3 } & Ripen peel & Unripe peel \\
\hline Ethyl acetate & 190 & 155 \\
\hline Acetone & 295 & 210 \\
\hline Ethanol & 340 & 307 \\
\hline Methanol & 395 & 367 \\
\hline
\end{tabular}

Table 2: Flavonoid contents

\begin{tabular}{|l|c|c|}
\hline \multirow{2}{*}{ Extracts } & \multicolumn{2}{|c|}{ Flavonoid content (mg quercetin equivalent/ g material) } \\
\cline { 2 - 3 } & Ripen peel & Unripe peel \\
\hline Ethyl acetate & 270 & 245 \\
\hline Acetone & 380 & 369 \\
\hline Ethanol & 465 & 395 \\
\hline Methanol & 482 & 425 \\
\hline
\end{tabular}

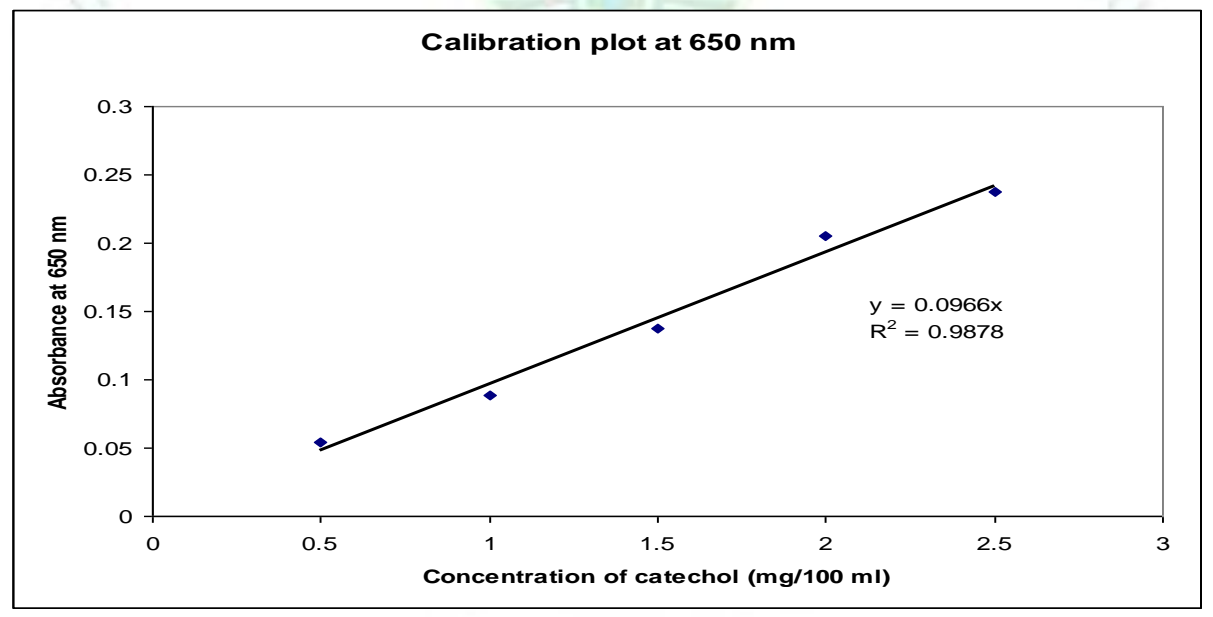

Figure 1: Calibration plot for phenolic determination

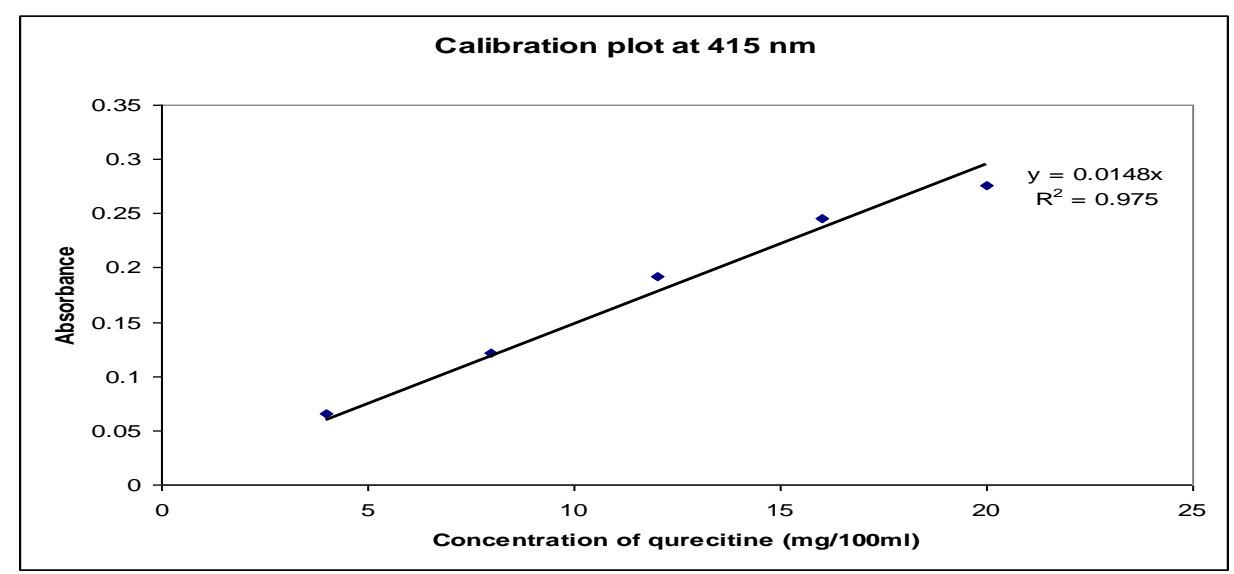

Figure 2: Calibration plot for flavonoid determination 


\section{CONCLUSION}

The present investigation revealed that citrus limon peel extracts contain significant amount of phenols and flavonoids. The objective of this study was to get information of the amount of phenolics and flavonoids from peel of citrus limon available from selected region of north eastern India. Further intention of this study is to correlate relationship of these secondary metabolites to possible biological activities and evaluate citrus limon as a potential source of natural bioactive chemicals.

\section{ACKNOWLEDGEMENT}

The authors are thankful to the principal, S.P. College, Pune-411030, India for providing the necessary support to carry out this work.

\section{REFERENCES}

1. Kahkone MP, Hopia AI, Vourela JH, Rauha JP, Pihlaja K, Kujala TS, Heinonen M, Antioxidant activity of plant extracts containing phenolic compounds, J Agric Food Chem, 1999; 47: 3954-3962.

2. Citrus fruit biology, tehnology and evaluation. Ladaniya: Academic Press; 2008.

3. Mohammadian MA, Mobram ZI, Sajedi RH, Bioactive compounds and antioxidant capacities in the flavedo tissue of two citrus cultivars under low temperature, Braz J Plant Physiol, 2011; 23(3): 203-208.

4. Mukhim C, Nath A, Deka B, Swer TL, The Bioscan, 2015; 10(2): 535-537.
5. Varies PS, Indian medicinal plants. Kottakkal: Arya Vaidya Sala; 2006; 2:97-100.

6. Munne S, Parwate D, Ingle V, Nagpurkar V, Evaluation of the anthelmintic activity of citrus limon juice sacs, Int $\mathrm{J}$ Pharma Professional's Research, 2011;2(2).

7. Fejzić A, Ćavar S, Phenolic Compounds and Antioxidant Activity of Some Citruses, Bulletin of the Chemists and Technologists of Bosnia and Herzegovina, 2014; 42:1-4.

8. Barua P, Yield, fruit quality and water productivity of drip fertigated Assam Lemon (Citrus limon). Internat $\mathrm{J}$ Agric Engg., 2013; 6(2):339-344.

9. Chaliha BP, Barua AD, Siddappa GS, Assam limon as a source of pactin, Indian Food Packer, 1963, XVII(3).

10. Sarmah N, Kumari S, Comparative study of antibacterial activity of ripen and unripen Indigenous Citrus union of Assam, India, Int $\mathrm{J}$ Advancements in Research \& Technology, 2013; 2(9):25-31.

11. Deb Roy S, Bania R, Chakraborty J, Goswami R, Laila R, Ahmed SA, Pharmacognostic, phytochemical, physicochemical property and antimicrobial activity studies of lemon peel oil, Nat Prod Plant Resource, 2012; 2(3):431435.

12. Muthiah PL, Umamaheswari M, Kumar AK, In vitro antioxidant activities of leaves, fruits and peel extracts of citrus, International Journal of Phytopharmacy Research Article, 2012; 2(1):13-20.

13. Malik EP, Singh MB, Plant Enzymology and Hittoenzymology. $1^{\text {st }}$ Ed. New Delhi: Kalyani Publishers; 1980. P. 286.

14. Mervat MM, H El-Far, AA Taie, Antioxidant activities, total anthrocynins, phenolics and flavonoids contents of some sweet potato genotypes under stress of different concentrations of sucrose and sorbitol, Australian J Basic Applied Sc, 2009; 3:3609-3616. 